\title{
Unilateral Stage 1A Macular Hole Secondary to Low-Energy Nd:YAG Peripheral Iridotomy
}

\author{
Jonathan C. Tsui ${ }^{1}$, Steven J. Marks ${ }^{1}$ \\ 1. Ophthalmology, Geisinger Medical Center, Danville, USA
}

Corresponding author: Jonathan C. Tsui, jctsui7@gmail.com

\begin{abstract}
Macular hole formation is a rare complication of laser peripheral iridotomy (LPI) and may cause permanent scotomas. This case describes macular hole formation after $2.8 \mathrm{~mJ} \mathrm{Nd}$ :YAG laser energy application in a patient with vitreomacular attachment. A literature review of a limited number of case reports shows that older patients who developed holes after LPI had more visually-significant and advanced stage holes that required surgical retinal repair, whereas younger patients had less visually-significant and mild stage holes with a spontaneous resolution on optical coherence tomography (OCT).
\end{abstract}

Categories: Ophthalmology

Keywords: macular hole, lpi, iridotomy, nd:yag, laser

\section{Introduction}

Laser peripheral iridotomy (LPI) is a common procedure used by comprehensive and glaucoma ophthalmologists to prevent and treat acute angle-closure glaucoma. However, there may be anterior segment adverse effects including hyphema, iritis, and corneal endothelial damage [1]. In addition, posterior segment complications include malignant glaucoma and retinal detachment [2,3]. Rarely, macular holes have been reported after LPI postulated to be from the concussive force on the anterior hyaloid face propagated within the vitreous cavity [4]. To the authors' knowledge, this case demonstrates the lowest amount of energy reported to cause macular hole formation after LPI. In addition, iatrogenic stage 1A macular holes may cause permanent scotomas.

\section{Case Presentation}

A 56-year-old Caucasian male was referred to our department for evaluation of bilateral anatomic narrow angles. Visual acuity was 20/20 in both eyes with an intraocular pressure of $18 \mathrm{~mm} \mathrm{Hg}$ bilaterally. Gonioscopic examination revealed blue irides with narrow, occludable angles bilaterally. Fundus examination revealed no evidence of optic nerve or vitreomacular pathology. Preoperative spectral-domain optical coherence tomography (OCT) demonstrated mild asymptomatic vitreomacular adhesion in the right eye and vitreomacular attachment in the left eye (Figure 1).

Review began 01/05/2021 Review ended 01/07/2021 Published 01/10/2021

๑) Copyright 2021

Tsui et al. This is an open access article distributed under the terms of the Creative Commons Attribution License CC-BY 4.0., which permits unrestricted use, distribution, and reproduction in any medium, provided the original author and source are credited.
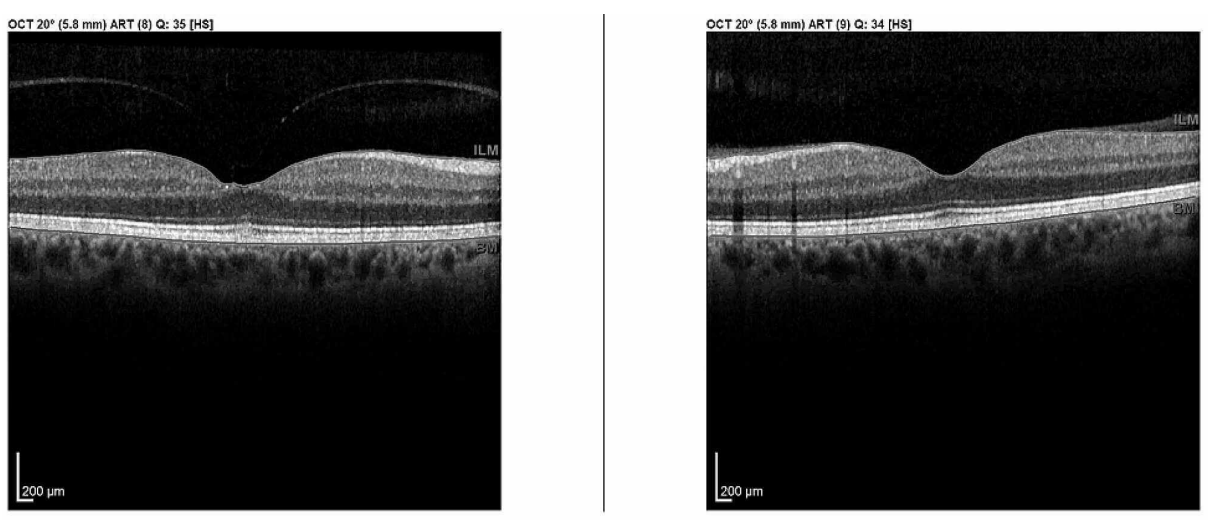

FIGURE 1: Preprocedural OCT macula horizontal raster demonstrating decreased area of vitreomacular attachment in the right eye compared to the left eye.

ОCT: optical coherence tomography

We proceeded with a laser peripheral iridotomy (LPI) of the right eye using Nd:YAG laser requiring two shots 


\section{Cureus}

and total energy of $2.8 \mathrm{~mJ}$. A patent superior iridotomy was confirmed at the slit-lamp. Eleven days later, the patient presented with abnormal visual disturbance of the right eye noting a dark spot in the center of his vision when reading. Visual acuity was 20/25 in the affected eye and fundus examination revealed a yellow foveolar spot. OCT demonstrated a new stage 1A macular hole of the right eye (Figure 2).

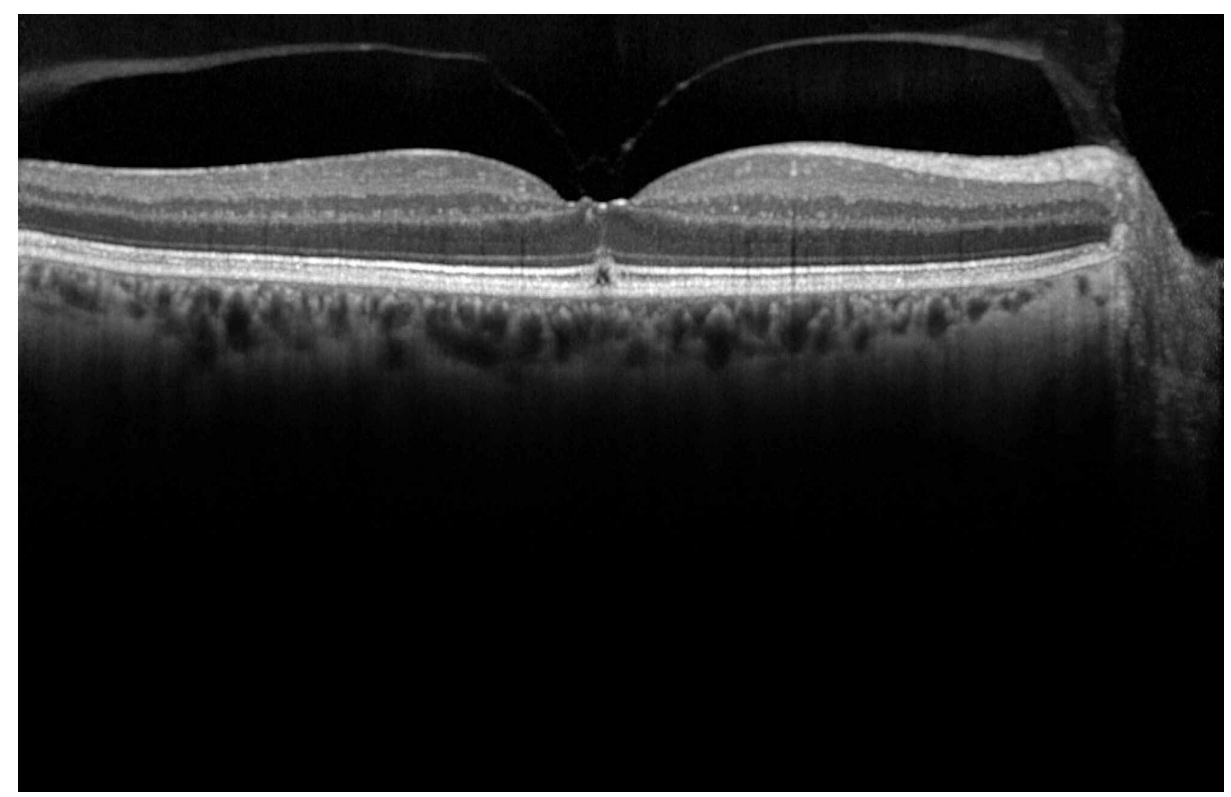

FIGURE 2: Postprocedural OCT macula horizontal raster of the right eye demonstrating a stage $1 \mathrm{~A}$ macular hole.

OCT: optical coherence tomography

At four-week follow-up, the patient did not note any improvement in his central scotoma although OCT revealed resolution of the vitreomacular traction (Figure 3). 


\section{Cureus}

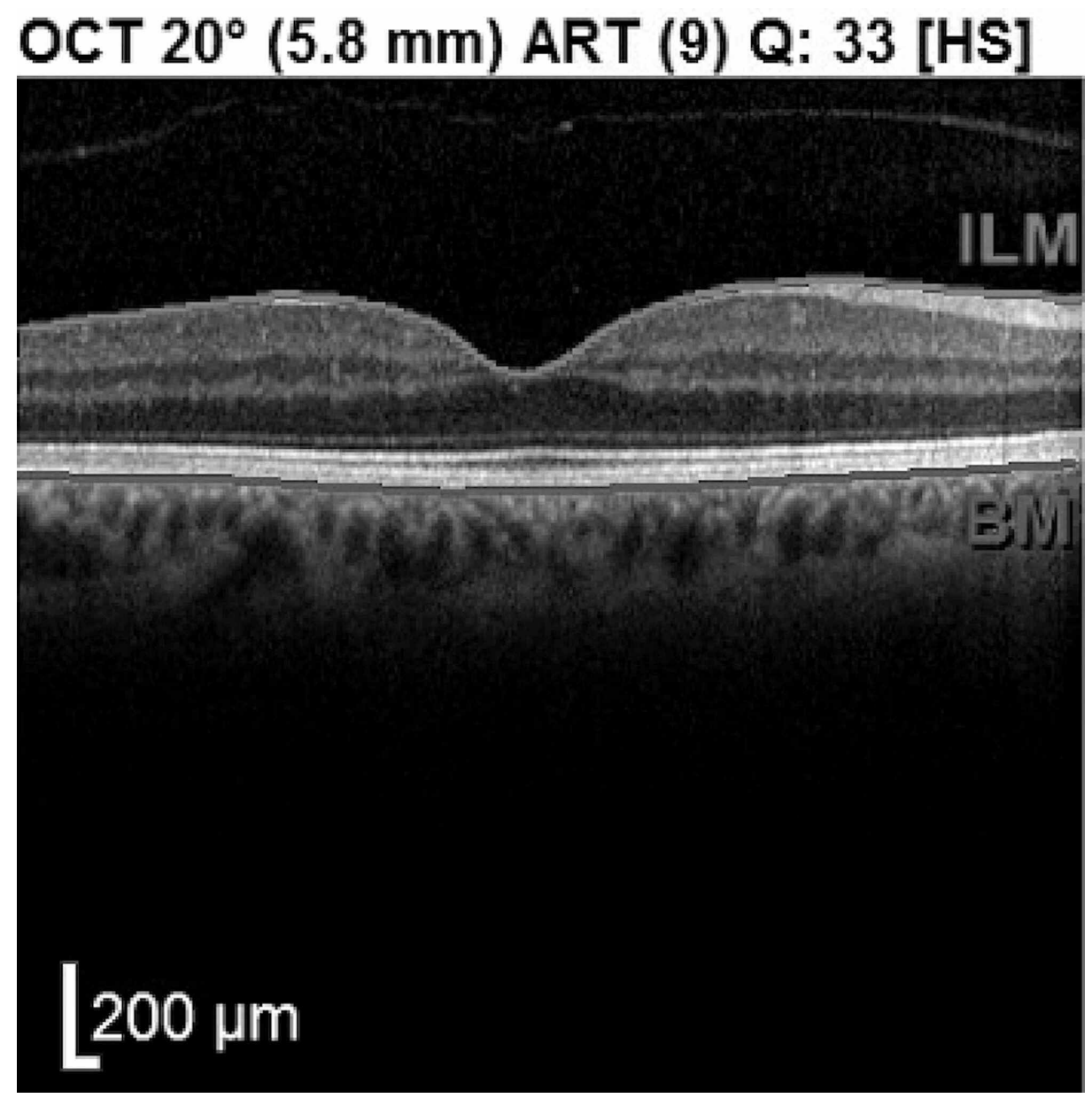

FIGURE 3: Post-observational OCT macula horizontal raster of the right eye demonstrating anatomic resolution of the stage $1 \mathrm{~A}$ macular hole and a posterior vitreous detachment.

OCT: optical coherence tomography

Six weeks later, the patient presented for laser peripheral iridotomy of the left eye. A total of two shots requiring $3.2 \mathrm{~mJ}$ of energy was required to create a patent superior iridotomy. Upon routine follow-up, the macular examination remained normal in the left eye. The patient continued to experience a central scotoma in his right eye.

\section{Discussion}

The mechanism of macular hole formation after LPI has been postulated to be secondary to plasma formation and photodisruption caused by Nd:YAG force extending into the vitreous cavity. This patient demonstrated macular hole formation after LPI in his right eye and no hole formation after LPI in his left eye although similar energy and technique were utilized bilaterally. This asymmetric result after similar procedures was most likely the result of varying preprocedural levels of vitreomacular attachment in each eye (Figure 1).

In the patient's right eye there was a decreased area of vitreomacular attachment compared to the left eye. Although similar Nd:YAG force was propagated posteriorly, the smaller vitreomacular interface in the right eye caused an increased level of pressure on the retina compared to the left eye. The left eye had a greater posterior hyaloid attachment and the force utilized, although technically $0.4 \mathrm{~mJ}$ higher in the left eye, is believed to be distributed to a larger area of vitreomacular attachment which translated to greater force dispersion and no resultant hole formation.

Syed et al found that increasing age is correlated with an increasing shift in the percentage of patients with partial vitreous separation to a higher proportion of complete posterior vitreous detachment (PVD) [5]. In the $50-54$ age group, $71.2 \%$ were found to have partial vitreous separation and $1.5 \%$ were found to have a complete PVD. In contrast, in the 65-69 age group, only $44.7 \%$ were found to have partial vitreous separation 
In a review of the literature, one other eye has been reported to have developed a stage 1 macular hole after LPI. In addition, there have been three eyes from two patients who developed stage 4 macular holes $[4,6,7]$. In this small sample of this rare complication, those who developed stage 1 macular holes were younger (54 and 60), whereas those who developed stage 4 macular holes were older (64 and 69) [4,6,7]. This suggests that the development of advanced macular holes after LPI increases with age in patients who have not yet developed a posterior vitreous detachment, possibly due to decreased area of the vitreomacular interface. Nonetheless, although older patients had a worse postprocedural visual acuity consistent with stage 4 macular holes, these patients experienced an improvement in visual acuity postvitrectomy (Table 1 ).

\begin{tabular}{|c|c|c|c|c|c|c|c|}
\hline Author & Age & Eye & LPI Power (mJ) & Hole Stage & Initial Va & Post-LPI Va & Follow-up Va \\
\hline Current study & 56 & OD & 2.8 & 1 & $20 / 20$ & $20 / 25$ & $20 / 25$ \\
\hline Anderson et al., 2006 [4] & 60 & os & 49.2 & 1 & $20 / 20$ & $20 / 30$ & $20 / 20$ \\
\hline Sar et al., $2015[7]$ & 64 & os & 5.6 & 4 & $6 / 9$ & $6 / 36$ & $6 / 9$ \\
\hline \multirow[t]{2}{*}{ Acharya et al., 2008 [6] } & 69 & OD & 70 & 4 & $6 / 6$ & $6 / 24$ & $6 / 12$ \\
\hline & & os & 52.8 & 4 & $6 / 6$ & $6 / 60$ & $6 / 9$ \\
\hline Follow-up visual acuity is $\mathrm{p}$ & ervatio & al for $s$ & age 1 macular holes & post-vitrectom & or stage $4 \mathrm{~m}$ & ular holes. & \\
\hline LPI: laser peripheral iridotc & : oculus & sinister & OD: oculus dextrus & & & & \\
\hline
\end{tabular}

\section{Conclusions}

This case supports the literature in the development of macular hole formation as a side effect after LPI and the potential of developing a permanent visual scotoma. In addition, it highlights that preprocedural OCT evaluation of vitreomacular anatomy may help guide the counseling of posterior segment complications prior to LPI. Furthermore, the case highlights the value of a follow-up dilated fundus examination. A review of this rare complication in this small sample demonstrates that older patients who developed holes after LPI were more visually-significant and advanced stage holes that required surgical retinal repair, whereas younger patients experienced less visually significant and early-stage holes with a spontaneous resolution on OCT.

\section{Additional Information \\ Disclosures}

Human subjects: Consent was obtained by all participants in this study. Geisinger IRB issued approval 2020-0965. RDW determination - activity does not meet the definition of research. Conflicts of interest: In compliance with the ICMJE uniform disclosure form, all authors declare the following: Payment/services info: All authors have declared that no financial support was received from any organization for the submitted work. Financial relationships: All authors have declared that they have no financial relationships at present or within the previous three years with any organizations that might have an interest in the submitted work. Other relationships: All authors have declared that there are no other relationships or activities that could appear to have influenced the submitted work.

\section{References}

1. Wu SC, Jeng S, Huang SC, Lin SM: Corneal endothelial damage after neodymium:YAG laser iridotomy. Ophthalmic Surg Lasers. 2000, 31:411-416.

2. Brooks AM, Harper CA, Gillies WE: Occurrence of malignant glaucoma after laser iridotomy. Br J Ophthalmol. 1989, 73:617-620. 10.1136/bjo.73.8.617

3. Bilateral nonrhegmatogenous retinal detachment following neodymium-YAG laser iridotomies. Arch Ophthalmol. 1986, 104:1134. 10.1001/archopht.1986.01050200040034

4. Anderson JE, Gentile RC, Sidoti PA, Rosen RB: Stage 1 macular hole as a complication of laser iridotomy . Arch Ophthalmol. 2006, 124:1658-1660. 10.1001/archopht.124.11.1658

5. Syed Z, Stewart MW: Age-dependent vitreous separation from the macula in a clinic population . Clin Ophthalmol. 2016, 10:1237-1243. 10.2147/OPTH.S99635

6. Acharya N, Munshi V, Sharma T: Bilateral macular holes immediately following Nd:YAG laser peripheral iridotomy. Photomed Laser Surg. 2008, 26:615-616. 10.1089/pho.2008.2243

7. Sar S, Sinha S, Mitra S: Unilateral full-thickness macular hole formation following low-energy Nd:YAG 


\section{Cureus}

peripheral iridotomy. J Glaucoma. 2015, 24:14-15. 10.1097/IJG.0000000000000097 